\title{
Hemiunu Used Numerically Tagged Surface Ratios to Mark Ceilings inside the Great Pyramid Hinting at Designed Spaces Still Hidden Within
}

\author{
Manu Seyfzadeh \\ Institute for the Study of the Origins of Civilization (ISOC) ${ }^{1}$, Boston University's College of General Studies, \\ Boston, USA \\ Email: manu@cheopspyramid.com
}

How to cite this paper: Seyfzadeh, M. (2018). Hemiunu Used Numerically Tagged Surface Ratios to Mark Ceilings inside the Great Pyramid Hinting at Designed Spaces Still Hidden Within. Archaeological Discovery, 6, 319-337.

https://doi.org/10.4236/ad.2018.64016

Received: September 10, 2018

Accepted: October 5, 2018

Published: October 8, 2018

Copyright $\odot 2018$ by author and Scientific Research Publishing Inc. This work is licensed under the Creative Commons Attribution International License (CC BY 4.0).

http://creativecommons.org/licenses/by/4.0/

\begin{abstract}
In 1883, W. M. Flinders Petrie noticed that the vertical thickness and height of certain stone courses of the Great Pyramid ${ }^{2}$ of Khufu/Cheops at Giza, Egypt markedly increase compared to those immediately lower periodically and conspicuously interrupting a general trend of progressive course thinning towards the summit. Having calculated the surface area of each course, Petrie further noted that the courses immediately below such discrete stone thickness peaks tended to mark integer multiples of $1 / 25$ th of the surface area at ground level. Here I show that the probable architect of the Great Pyramid, Khufu's vizier Hemiunu, conceptualized its vertical construction design using surface areas based on the same numerical principles used to design his own mastaba in Giza's western cemetery and conspicuously used this numerical theme to mark the location of known spaces inside the Great Pyramid. The theme is not only consistent with some spaces proposed still awaiting proof but also suggests there are some still undiscovered.
\end{abstract}

\section{Keywords}

Great Pyramid, Khufu, Cheops, Hemiunu, Egypt, Giza, Pyramid, Architecture, Hidden Chamber

\footnotetext{
${ }^{1}$ URL: https://www.bu.edu/cgs/citl/institute-for-the-study-of-the-origins-of-civilization/.

${ }^{2}$ During the era of Khufu in the language of the ancient Egyptians, this pyramid was named khwfw akhet, "Khufu's Horizon". The pyramid of Khafre was named khaf-re wr, "Great is Khaf-re". Even though the term Great Pyramid therefore more accurately refers to Khafre's pyramid, the popular convention has been to use that designation for Khufu's Horizon and for clarity I will adhere to that popular convention.
} 


\section{Introduction}

Khufu's pyramid (a.k.a. Cheops Pyramid, the Great Pyramid, Khufu's Horizon) was constructed in the $26^{\text {th }}$ century B.C.E. during the reign of Khufu according to the current historical model. Its likely architect was Khufu's (half-) nephew and his early vizier Hemiunu. In a prior article, I presented evidence that essential architectural features of Khufu's pyramid like its base length, height, angle, and concavity-creating indent were cleverly incorporated by Hemiunu into the original dimensions of his own mastaba Giza 4000 (G 4000) located in the western cemetery nearby, before a later remodel extended both its length and width (Seyfzadeh, 2018). In addition, the scale-up factors five (5) and eight (8) appear to have carried special significance to Hemiunu. The Meydum Pyramid's exterior dimensions compared to those of Khufu's Pyramid are proportionally smaller by $5 / 8$. Hemiunu's mastaba's original long side appears to have embedded 1/5 (i.e. 88 royal Egyptian cubits; abbr.: rc; $1 \mathrm{rc}=0.5236 \mathrm{~m}, 20.614$ in) of the base length of Khufu's pyramid at 440 rc. The later-extended long and short sides of G 4000 were likely designed to be five times as long as the length and width of the so-called King Chamber inside Khufu's pyramid $(20 \times 10 \mathrm{rc})$. The basic horizontal architectural unit used was $11 \mathrm{rc}$ which is $1 / 8$ of G 4000 and the pyramid's core masonry was likely designed with eight sides by indenting its faces by $0.92 \mathrm{~m}=1.76 \mathrm{rc}=8 \times 1 / 1000 \times 220 \mathrm{rc} \sim 1 \mathrm{rc} 1$ palm 1 finger (Seyfzadeh, 2018). It therefore appears as if Hemiunu used his own mastaba as an architectural blueprint of the Great Pyramid.

This numerical theme of "five and eight" may have astronomic and hence theological roots in ancient Egypt. The planet Venus appears low over the horizon at dusk and dawn with a near perfect periodicity of five inferior conjunctions per eight sidereal Earth years each observable as the period ( $3651 \frac{1}{4}$ days) between two helical risings of the star Sirius. Evidently, both Venus and Sirius were alternate manifestations of the falcon god Horus (Krauss, 1997: pp. 216-222; Allen, 2005: p. 47, Recitation 172). The numbers five and eight were also deeply embedded in Egyptian religious thought. In the cosmogony of Hermopolis, eight primordial gods created the world with a Lotus flower (which often possesses an eight-petaled inner calyx) rising from the cosmic sea giving birth to the sun. The upper priesthood of Hermopolis consisted of the Five of the House of Thoth and Hemiunu was their greatest, presumably presiding member based on inscriptions found in his tomb. In short, the numbers five and eight were likely of special significance to the ancient Egyptians of Khufu's time originating from astronomic periods, converted to theological teaching, and possibly architecturally expressed in pyramids and mastabas.

When W.M. Flinders Petrie, a British surveyor who investigated the Giza Pyramids in the late $19^{\text {th }}$ century, examined and measured Khufu's pyramid, the exterior façade of casing stones had long been stripped and only the core masonry remained as it still appears today. Among many measurements, Petrie determined the incremental and cumulative vertical thickness of the four, now 
denuded pyramid corners with each added course of limestone blocks and reported these data in 1883 (Petrie, 1883: Plate VIII). He noted that the general trend of lesser elevation with each added level was periodically interrupted by a significantly thicker course followed by a series of gradually thinning courses. One such thicker course, the $35^{\text {th }}$, can easily be seen nowadays from all four sides of Khufu's pyramid (Figures 1-3) and the periodic occurrence of this course height "Peaking and Decay" throughout its walls from bottom to summit creates the visual effect of a "feathered" texture (or "waves"; personal communication Jean-Pierre Houdin) when the pyramid is viewed from a distance. Petrie annotated

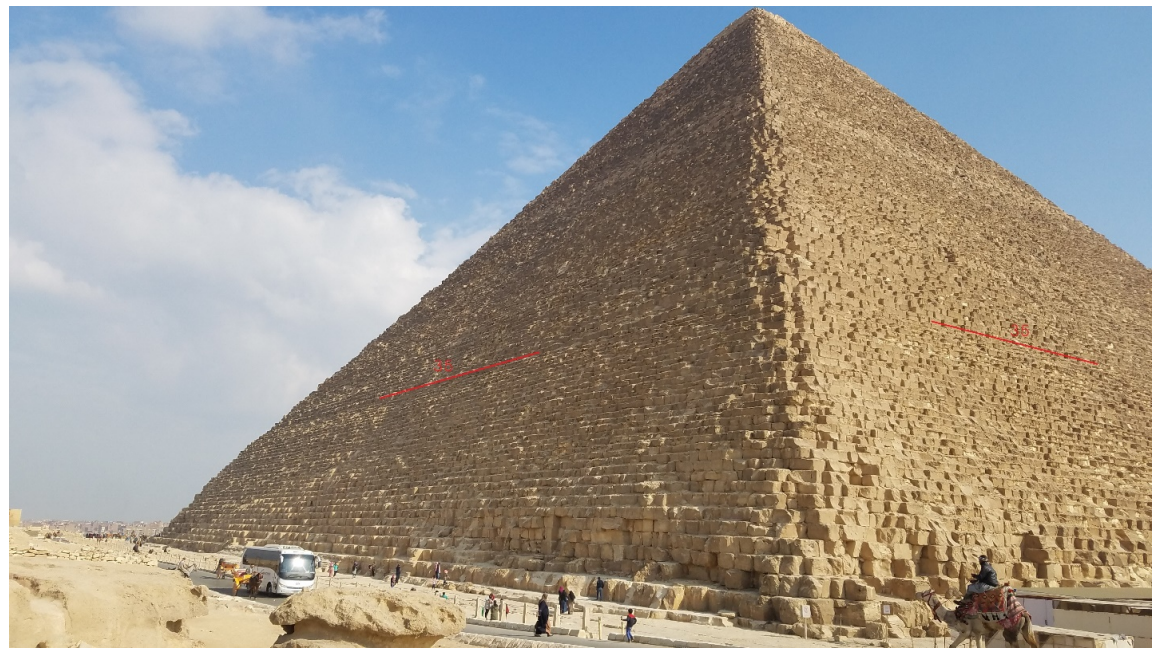

Figure 1. Southwest corner of the Great Pyramid showing the position of the 35th course which runs immediately above the Queen Chamber's roof inside. The corner edge is one of four where Petrie made his measurement of course thickness up the 203 currently surviving course levels. Photograph taken by the author in February 2017; modified.

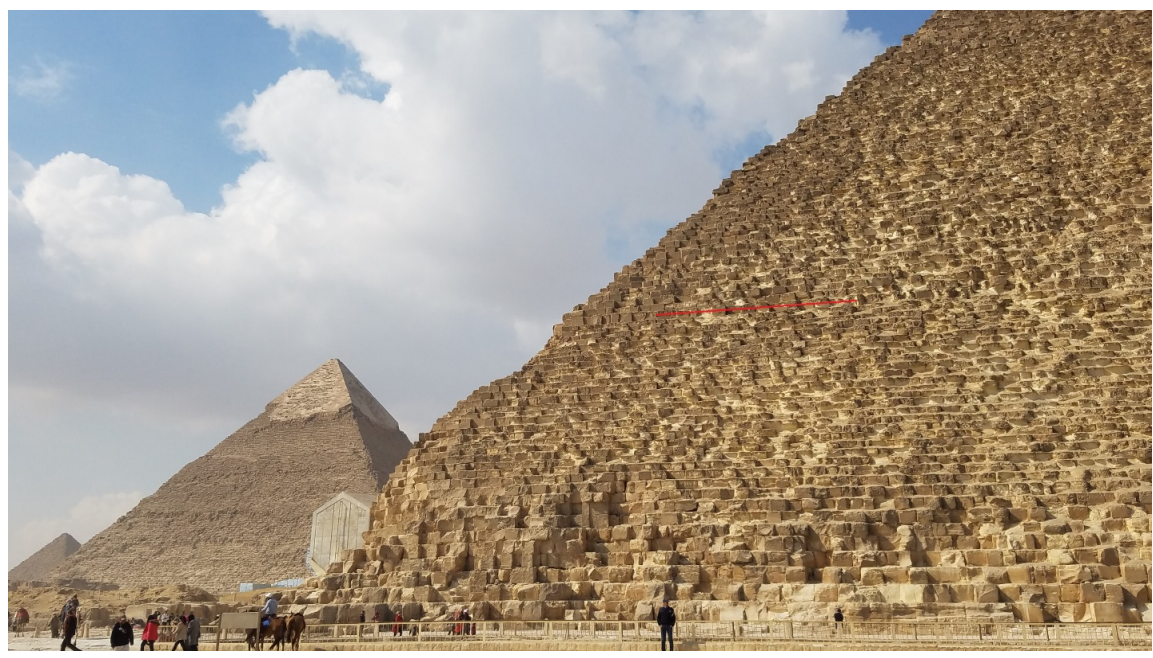

Figure 2. The $35^{\text {th }}$ course is marked in red on the east side of the Great Pyramid shown in the foreground. Its thickness visibly stands out relative to that of the courses immediately below. Khafre's and Menkaure's pyramids are in the background. Photograph taken by the author in February 2017; modified. 


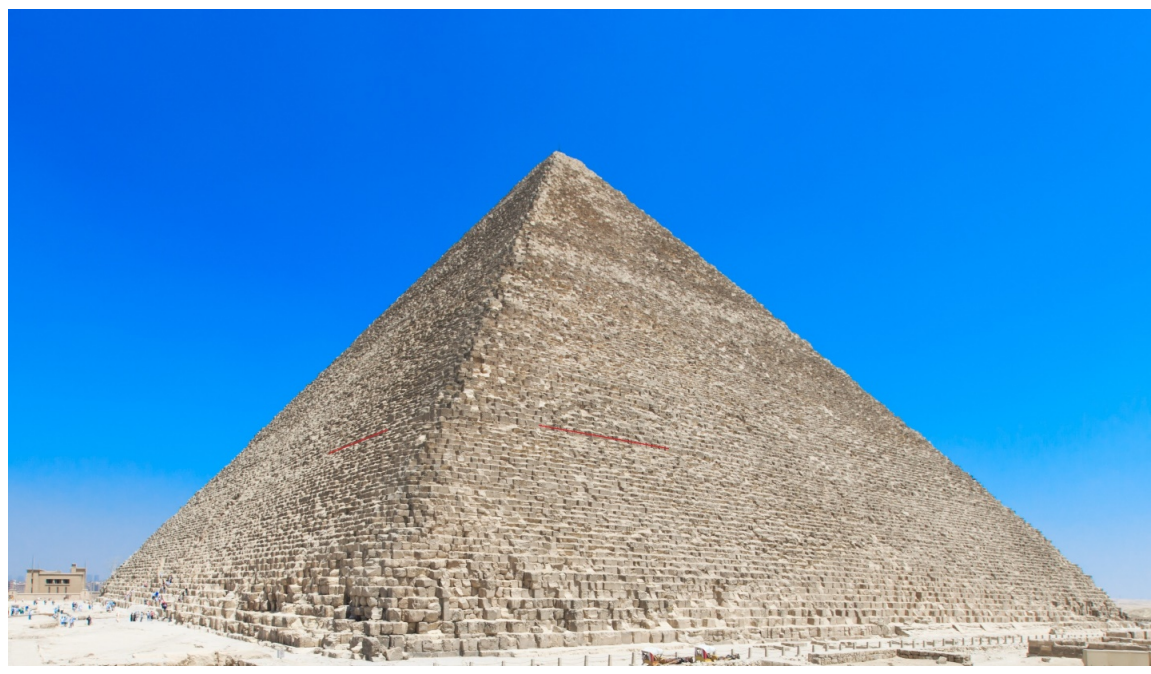

Figure 3. The $35^{\text {th }}$ course is marked in red on the north and west sides of the Great Pyramid. Photograph by Adobe Photostock, license \# 102571012; modified.

these thickness peaks at the top of his plot because he had realized that the pyramid levels immediately below had surface areas which were near round-number multiples of $1 / 25^{\text {th }}$ the surface area of the pyramid at the base, i.e. $(440 \mathrm{rc})^{2}$. The significance of these peaks and ratios however remains a mystery to date and it is not known if they were necessary architectural features, esoterically encode a message of the architect, or a random feature of how stones were cut and delivered to the construction zone from the quarries.

However, since this series of thickness peaks on the way up the pyramid appears non-random and given that some amount of computation would have been required to generate a numerical sequence based on surface area ratios, I reexamined Petrie's data to see if they comport with what I earlier observed in the design of Hemiunu's mastaba and if they may reveal heretofore unappreciated features of Khufu's pyramid, for example as yet undiscovered passages, chambers or corridors. While hidden voids have been proposed to exist (e.g. Morishima et al., 2017), evidence is difficult to procure non-invasively and so numerical clues, especially when corroborated with architectural evidence, may guide researchers where to look with non-invasive means. Furthermore, the mere identification of voids does not prove they were intentionally made and data which suggest they exist may be still challenged as artifactual (e.g. Lightbody, 2018). In the absence of a blueprint by the architect unequivocally demonstrating intended design, a numerical theme associated with voids, on the other hand, especially when also found in the purported architect's own tomb, is powerful evidence of what the architect meant to conceive.

\section{Methods}

Petrie published vertical thickness (i.e. course height) data pertaining to the 203 nowadays remaining courses of Khufu's pyramid as a composite column plot of 4-corner measurements (i.e. each column represents four measurements taken at 
the N.E., S.E., S.W., and N.W. corners making the column tops look striped) relative to the overall height of the course in the pyramid (Petrie, 1883: Plate VIII). From this visual representation of successive pyramid layers' heights, one can observe at least 23 discontinuous, "sudden" increases in the height of some courses within an overall context of generally decreasing thickness as one ascends the pyramid to the summit. Such distinct peaks are, with few exceptions, followed by a series of gradually thinning courses resuming the overall trend towards the summit. Consequently, some of these consecutive peaks have as few as one thinner layer between and some as many as eighteen. At the top of Petrie's plot, some but not all peaks show fractions of twenty-fifths $\left(1 / 25^{\text {th }}\right)$ explained in the legend:

"The levels of twenty-fifths of the area of the pyramid section are marked along the top, and appear to coincide with the thicker courses."

Repeating Petrie's calculations it becomes clear that these notations refer to courses immediately below such peaks. For example, the thirty-fifth course (\#35) is a much thicker course than the preceding courses \#23-34 which show a gradual thinning trend interrupted by \#35 (Petrie, 1883: Plate VIII). Petrie's “16/25" written above refers to the ratio of the surface area of course \#34 relative to that at the base, i.e. the squared length of the pyramid sides at ground level when they were fully cased (=440 rc). Therefore, "The levels of twenty-fifths" noticed by Petrie are numerically "round" integer fractions $(16 / 25,14 / 25,10 / 25,9 / 25$, etc., as opposed to $15.65 / 25,14.32 / 25$ for example) denoting surface area ratios of those courses which immediately precede a "suddenly" thicker course going up the pyramid. I am going to refer to these courses as "pre-peak" (abbr. P.P.) in this paper.

To recapitulate Petrie's computations in deriving these fractions and to apply this process to all courses immediately below the 23 thickness peaks observed, I used his cumulative height measurements on the X-axis of his plot marked "N.E." and "S.W." and generated an average between the two measured heights corresponding to these courses. After converting inch to royal Egyptian cubits at $20.61^{3}$ inch per rc, I calculated the surface area in square cubits of each of these pre-peak courses using the known angle of the pyramid (known as the seqed in ancient Egypt) of 51/2 rc base recess (or "run") per $7 \mathrm{rc}$ rise in overall height ${ }^{4}$ :

P.P. Surface Area $=\left[440 \mathrm{rc}-(\right.$ P.P. height in inch $/ 20.614 \mathrm{in} / \mathrm{rc}) \times\left(5 \frac{1}{2} \mathrm{rc} / 7 \mathrm{rc}\right)$ $\times 2]^{2}$

From these surface areas, the pre-peak surface area ratios (SARs) relative to the pyramid's base at $(440 \mathrm{rc})^{2}=193,600 \mathrm{rc}^{2}$ were computed and the resulting decimal ratios were converted to multiples of $1 / 25^{\text {th }}$ as per Petrie's notation at the top of his plot and within the margin of error of 13 parts per 100 which thus includes course \#34 at $16.11 / 25^{\text {th }}$. Petrie's representation of the data as multiples of

${ }^{3}$ This conversion from inch to royal cubits is based on Lehner and Goodman's (Dash, 2012) average exterior casing length measurements in meters combined with the generally held assumption that the base length was intended to be $440 \mathrm{rc}$ and the conversion of 1 imperial inch per 0.0254 meters. ${ }^{4}$ The seqed was the ancient Egyptians method to construct the angle of a pyramid using a step-wise process in which the base length of each successive course was let in, i.e. made shorter, by a certain amount per one-cubit rise depending on what angle was desired. 
$1 / 25^{\text {th }}$ appears to be a good match of the data within this reasonable margin of error. Using 13 parts per 100 as a cut-off, I then defined all those peaks of the 23-total identified, which might belong to the sequence of round multiples of twenty-fifths. My inclusion criterion for the definition of "round" in this study of Petrie's data is therefore any number which is within 13 parts per 100 of an integer.

\section{Results}

The choice of thicker courses was not random, but premediated. Below twenty-three observable peaks in stone course thickness, Petrie marked the pre-peak course of ten (Table 1). No mention is made of Petrie's exclusion criterion and why he excluded the other pre-peak SARs. However, the data show that four additional courses could be included using the criterion (13 parts per 100) employed in this study: Courses \# 21,117, 129, and 195. Their inclusion expands Petrie's set of ten to a total of twelve significant data points which conform to a sequence of integer multiples of $1 / 25^{\text {th }}$. The last two fractions close to the pyramid summit, $1 / 50^{\text {th }}$ and $1 / 100^{\text {th }}$ are not integer fractions of $1 / 25^{\text {th }}$ (i.e. $0.5 / 25^{\text {th }}$ and $0.25 / 25^{\text {th }}$ ) but instead represent successive halvings of $1 / 25^{\text {th }}$; this also appears non-random and so these courses are included in this analysis. The ratio $0.19 / 25$ (Table 1) could also be interpreted as $1 / 125^{\text {th }}$, but this does not affect the conclusions of this paper. The fact that these ratios conform to a numerical sequence based on round number fractions with the common denominator " 25 " and that all of them mark the imminent occurrence of thicker courses suggests a premeditated design theme and not a random coincidence. The remaining nine courses immediately below thickness peaks number $6,17,46,56,83,85,107$, 137 , and 149 do not significantly conform to this sequence.

Pre-Peak courses in the lower 2/5 of the Great Pyramid align with known structures inside the Great Pyramid and tend to be associated with ceilings. Figure 4 shows an illustration by Petrie (1883) with the position of all pre-peak courses, conforming to round fractions of twenty-fifths or not, in the lower $2 / 5^{\text {th }}$ of the Great Pyramid. Course \#6, whose SAR at $22.65 / 25^{\text {th }}$ is not an integer fraction of $1 / 25^{\text {th }}$, is nevertheless associated with the ceiling of that part of the descending passage which joins the ascending segment (Figure 4). A similar illustration by Maragioglio and Rinaldi (1965: Tav. 3) confirms this position of course \#6.

Course 17's SAR at $19.79 / 25^{\text {th }}$ (Table 1) does not fulfill the criterion of a whole number multiple of $1 / 25^{\text {th }}$ and is not associated with the ceiling of a known pyramid structure.

Course \#21 $\left(19 / 25^{\text {th }}\right)$ is associated with the notch created by the lower pair of chevrons above the main entrée in the north wall (Figure 5). This alignment is confirmed by Maragioglio and Rinaldi (1965: Tav. 2, Fig. 10; the top of \#21 is marked with the number $19.12(\mathrm{p}))$.

Course $34\left(16 / 25^{\text {th }}\right)$ is associated with the peak of the ceiling rafters of the Queen Chamber and this is confirmed by Maragioglio and Rinaldi, C.A (1965: Tav. 3). 
Table 1. Great Pyramid Surface Ratios of Pre-Peak Courses expressed as Fractions of 25. Listed are the twenty-three courses immediately below noticeable peaks in Petrie's plot of course thickness as a function of course height. Surface ratios were calculated as described in the Methods section. The third column shows all those pyramid courses whose surface ratios closely conform to integer multiples of $1 / 25^{\text {th }}$. In the fourth column, four new courses were identified whose surface ratios relative to the pyramid's square base also closely matches an integer multiple of $1 / 25^{\text {th }}$, or halvings thereof, but were not marked by Petrie. Course \#43 has a SAR of 13.94 which rounds to $14 / 25^{\text {th }}$ and it is this course which is noted in Petrie's plot to have a SAR expressed as a round number of twenty-fifths. Based on this paper's definition of a pre-peak plot, i.e. the course immediately below a significant increase in thickness, it is listed as "not Pre-Peak" in this table. Its significance is discussed under Results. The cut-off criterion used was a deviation from a perfect integer ratio by equal or greater than 13 parts per 100 to include Petrie's 16/25 value for the pre-peak course \#34 and course \#129.

\begin{tabular}{|c|c|c|c|}
\hline Pre-Peak Course \# & Surface Ratio in $1 / 25$ th & Petrie Sequence & Proposed Sequence \\
\hline 6 & 22.65 & & \\
\hline 17 & 19.79 & & \\
\hline 21 & 18.91 & & $19 / 25$ \\
\hline 34 & 16.11 & $16 / 25$ & $16 / 25$ \\
\hline 42 (Pre-Peak) & 14.16 & & \\
\hline 43 (not Pre-Peak) & 13.94 & $14 / 25$ & $14 / 25$ \\
\hline 46 & 13.26 & & \\
\hline 56 & 11.53 & & \\
\hline 66 & 10.05 & $10 / 25$ & $10 / 25$ \\
\hline 73 & 8.95 & $9 / 25$ & $9 / 25$ \\
\hline 83 & 7.71 & & \\
\hline 85 & 7.47 & & \\
\hline 89 & 7.03 & $7 / 25$ & $7 / 25$ \\
\hline 97 & 5.99 & $6 / 25$ & 6.25 \\
\hline 107 & 4.76 & & \\
\hline 115 & 4.06 & $4 / 25$ & $4 / 25$ \\
\hline 117 & 3.89 & & $4 / 25$ \\
\hline 129 & 2.87 & & $3 / 25$ \\
\hline 137 & 2.35 & & \\
\hline 143 & 2.00 & $2 / 25$ & $2 / 25$ \\
\hline 149 & 1.66 & & \\
\hline 161 & 1.12 & $1 / 25$ & $1 / 25$ \\
\hline 179 & 0.53 & $1 / 50$ & $1 / 50$ \\
\hline 195 & 0.19 & & $1 / 100$ \\
\hline
\end{tabular}




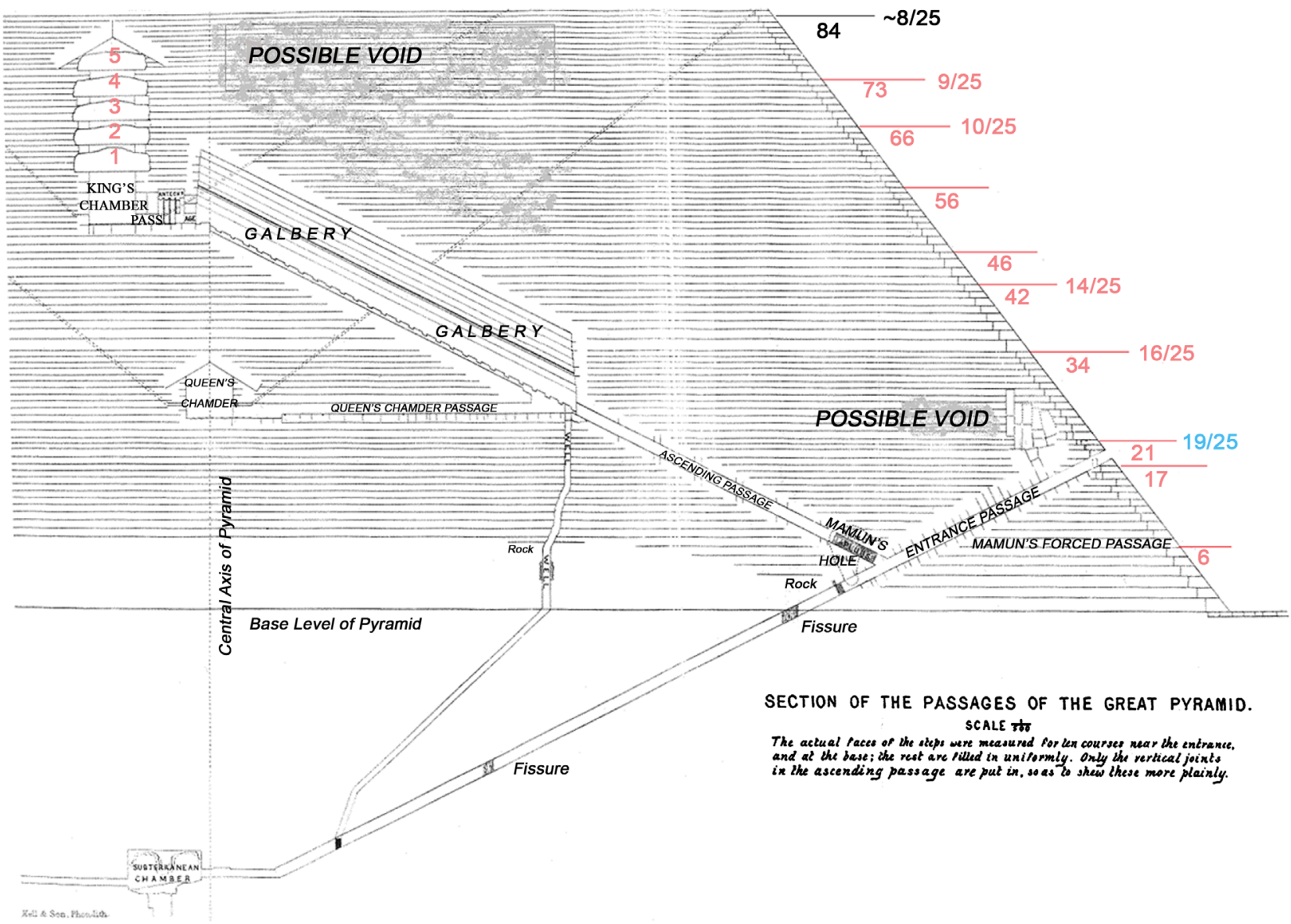

Figure 4. Illustration showing the location of pre-peak courses in the lower $2 / 5^{\text {th }}$ (below the $85^{\text {th }}$ course of 210 presumed total) of the Great Pyramid's north side. Pre-peak courses noted by Petrie on Plate VIII as inter fractions of $1 / 25^{\text {th }}$ are marked with their respective ratios in red color and those proposed in this paper in addition to Petrie's are in blue. At the top in black is shown course \#84, whose pre-peak course \#83 is conspicuously absent (there is no course with a round SAR of $8 / 25^{\text {th }}$ ) in the numerical sequence of round twenty-fifths and coincides with the top of the granite tower structure above the King Chamber. The five ceiling-elevating chambers within the granite tower above the King Chamber are numbered in red. The proposed voids recently detected by muon scanning and their possible orientations are shown as grey zones within the body of the pyramid. Note that in this illustration the casing stones are represented even though they no longer existed when Petrie came to Giza. Illustration by Petrie, 1883; Plate IX, modified. For fine details of the original illustration see: http://www.ronaldbirdsall.com/gizeh/petrie/photo/plate9.html.

Course \#42 $\left(14 / 25^{\text {th }}\right)$ intersects the approximate center, both vertically and lengthwise, of the Grand Gallery where it crosses the north shaft of the Queen Chamber in the horizontal plane (the north shaft runs west of the Grand Gallery and these two structures only appear to cross paths in this vertical, two-dimensional illustration). Here, there is a discrepancy between the drawing of Petrie and that of Maragioglio and Rinaldi, C.A (1965, Tav. 3) who show course \#40 to align with this architectural point (marked 34.77 in their figure). It is not clear if this discrepancy is due to an inaccuracy of either author's drawing or the inappropriate inclusion of course \#42 in the sequence based on the criterion chosen. The SAR of \#42 is $14.16 / 25^{\text {th }}$ and since this is the value furthest removed from an integer fraction in the entire sequence of twelve, this course may not mark a specific ceiling point of significance after all. 


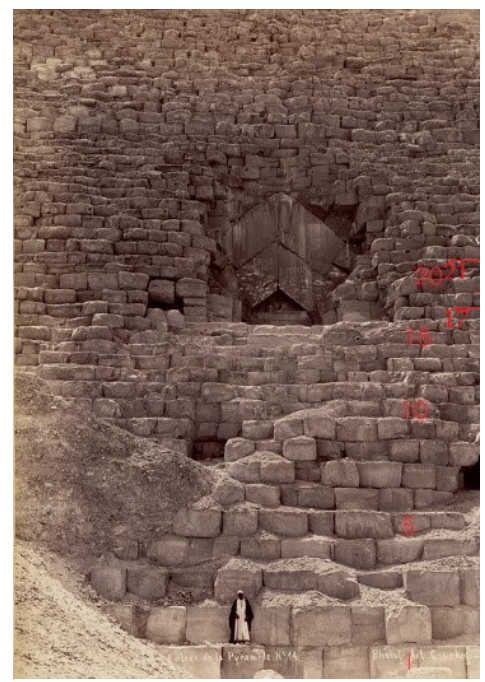

Figure 5. Main entrance to the Great Pyramid on its north wall. Shown in red are the course numbers and the tops of courses 17 and 21 are marked in red for orientation and to point to the thicker courses \#18 and \#22 immediately above. The thicker courses are immediately above in each case. Only \#21 appears to mark a ceiling specifically the bottom notch of the lower pair of chevrons arching over the entrée. Note that this photo shows the Great Pyramid in its current state without the casing stones. Photo courtesy of Boston Public Library: "The Entrance to Great Pyramid" created by William Vaughn Tupper (https://www.flickr.com/photos/boston_public_library/2469130012); modified. Creative Commons License.

However, \#43 though technically not a P.P. course, has a round-number SAR of $14 / 25^{\text {th }}$. This course does not have an association with a known ceiling inside the lower $2 / 5^{\text {th }}$ of the Great Pyramid. However, Jean-Pierre Houdin's model of the pyramid's interior includes two "Secret Rooms" (see Dassault Systèmes website at URL: https://blogs.3ds.com/perspectives/khufu\%E2\%80\%99s-secret-rooms/). It is possible that \#43 aligns with the base of the corbelled ceiling of these chambers proposed to rest a few courses above the Queen Chamber's roof (course \#35) and below the ground level of the King Chamber (course \#50), although Muon scanning did not detect them, if they exist. It is also possible that \#43 marks the ceiling of a different space from those proposed by Houdin and too small to be detected by Muon scanning or a space not in the path of the Muon stream measured.

Courses \#66 $\left(10 / 25^{\text {th }}\right)$ and \#73 $\left(9 / 25^{\text {th }}\right)$ correspond to the approximate tops of the irregular ceiling rafters of ceiling-elevating chambers 2 and 4 in the granite tower over the King Chamber.

Course \#84 corresponds to the level immediately above the peak of the ceiling rafters of the granite tower. Course 84 is not immediately below a thickness peak but is itself a thicker course. The SAR of the course immediately below, course $\# 83$, is not an integer multiple of $1 / 25^{\text {th }}$. Therefore, the $8 / 25^{\text {th }}$ SAR is conspicuously absent in the otherwise continuous sequence which begins at $10 / 25^{\text {th }}$ and ends at $1 / 100^{\text {th }}$ with the $195^{\text {th }}$ course. The only other exception is the also conspicuously absent $5 / 25^{\text {th }}$ SAR integer fraction. 
Pre-Peak and thicker courses in the upper $3 / 5^{\text {th }}$ of the Great Pyramid are not associated with any known interior structures. There are six courses with SARs conforming to the continuous sequence of $1 / 25^{\text {th }}$ in addition to two at $1 / 50^{\text {th }}$ and $1 / 100^{\text {th }}$ for a total of eight which are hence numerically non-random (Figure 6). No interior structure has ever been found in this part of the pyramid. However, an internal spiral ramp has been proposed (Brier \& Houdin, 2008: pp. 139-143).

The architect of the Great Pyramid conceptualized the base as a square of 5 units of 88 royal Egyptian cubits and used one such unit to design his own mastabas. In a prior publication (Seyfzadeh, 2018), I showed that the base dimensions of Hemiunu's mastabas G 4000 in the western cemetery were designed to represent essential architectural features of the Great Pyramid providing evidence that Hemiunu was in fact its architect and used his own mastabas to enshrine the blueprint of his pyramid design. The original length of G 4000 before its

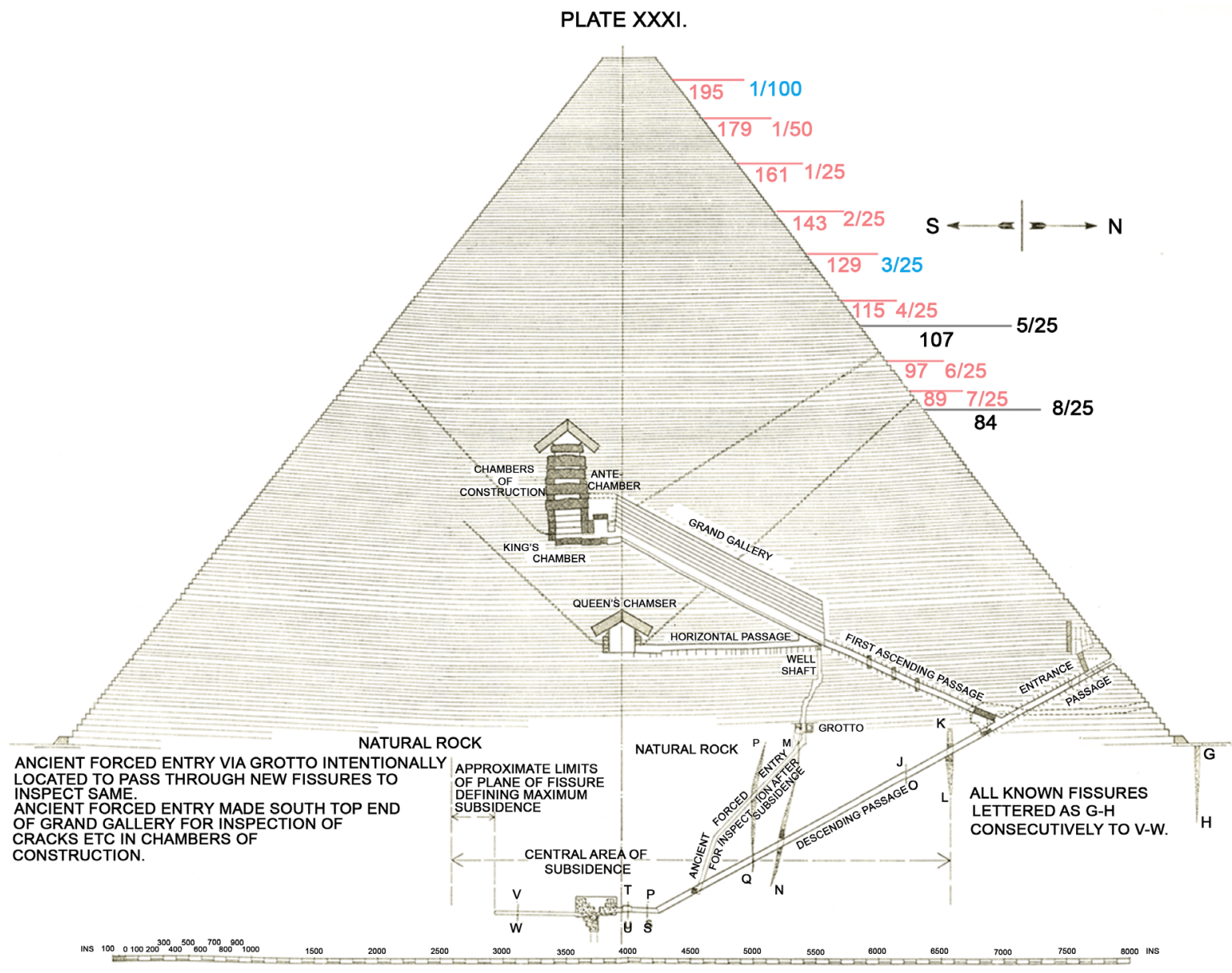

Figure 6. Illustration showing the approximate location of pre-peak courses in the upper $3 / 5^{\text {th }}$ (above the $85^{\text {th }}$ course of the presumed total of 210) of the Great Pyramid's north side. No known structures exist in the interior of the Great Pyramids corresponding to these courses. Illustration from The Great Pyramid: It's Divine Message by D. Davidson \& H. Aldersmith, 1936. London: Williams and Norgate Ltd.; modified. Photo file courtesy of William Struse, http://www.countdowntothemessiah.com. For fine details of the illustration follow this link to page 97:

https://archive.org/details/DavidDavidsonTHEGREATPYRAMIDLib.DavidsonTheGreatPyramidItsDivineMessage.pdf. 
later expansion was 89 rc 5 palms and 2 fingers ${ }^{5}$ long (47.00 meters; Junker, 1929: p. 132). The evidence suggests that Hemiunu purposefully added the fractional cubit amounts of $1 \mathrm{rc} 5$ palms 2 fingers to $88 \mathrm{rc}$ and 6 palms 3 fingers to 40 rc to enshrine both $1 / 5^{\text {th }}$ of the length of the Great Pyramid's base at $440 \mathrm{rc}$, the pyramid angle of $5 \frac{1}{2}$ palms per 1 cubit and the length of the indent of the four pyramidal faces $(0.92 \mathrm{~m}, 1 \mathrm{rc} 5$ palms 1 finger). This indentation produces concavities of the core masonry on all four sides (the casing layer was not indented; Glen Dash, personal communication) and thus the appearance of an eight-sided pyramid in certain lighting once it was stripped of its casing stones (Seyfzadeh, 2018).

The apparently non-random sequence of courses with SARs conforming to whole number multiples of $1 / 25^{\text {th }}$ suggest that Hemiunu conceptualized the base of the Great Pyramid as a square of five units $(5 \times 5=25)$, each $88 \mathrm{rc}$ long to more easily plan the vertical growth of the structure. In this way, he was able to preconceive surface areas of higher-up courses of architectural significance as integer fractions of $1 / 25^{\text {th }}$, and perhaps also $1 / 50^{\text {th }}$, and $1 / 100^{\text {th }}$. Therefore, he used the same conceptual unit of $88 \mathrm{rc}$ to design his own mastaba, the base of the Great Pyramid, and its vertical expansion.

In the upper $3 / 5^{\text {th }}$ of the Great Pyramid, the SARs $8 / 25$ and 5/25 are conspicuously absent as integer multiples in the otherwise continuous sequence. The numbers five and eight were of significant astronomical, theological, and architectural significance during the era in which Hemiunu lived, i.e. the Old Kingdom. The fact that the design employed an otherwise continuous, non-random numerical sequence based on surface ratios marking ceilings and thicker courses inside the Great Pyramid but omitted these two integer fractions suggests that they were of special significance to Hemiunu.

\section{Discussion}

Petrie observed that a comparison of successive heights of the 203 remaining courses of the Great Pyramid reveals a non-random pattern in whole-number multiples of twenty-fifths immediately below discrete reversals of a general course thinning trend. Adding to Petrie's insight that this pattern is based on surface ratios relative to the surface area of the base, four additional courses can be shown to expand the prior set of ten to fourteen.

In the lower $2 / 5^{\text {th }}$ of the body of the pyramid, these thickness peak-associated courses tend to mark the ceilings of known structures within and the thicker courses immediately following run above those ceilings. In the upper $3 / 5^{\text {th }}$, no known structures have been found to co-locate with these courses.

In an otherwise continuous set of twenty-fifths from $10 / 25^{\text {th }}$ to $1 / 25^{\text {th }}$, the courses whose surface area ratios could have closely conformed to $8 / 25^{\text {th }}$ and $5 / 25^{\text {th }}$ were not made large enough to generate these whole number ratios. Instead, two additional courses stand out at the top, $1 / 50^{\text {th }}$ and $1 / 100^{\text {th }}$, which

${ }^{5}$ A royal Egyptian cubit was divided into seven palms. Each palm was further divided into four fingers. A cubit, therefore, was twenty-eight fingers long. It was $\sim 0.524$ meters or $\sim 20.6$ inch. 
complete a set of ten marked courses in the upper $3 / 5^{\text {th }}$ of the pyramid. This non-random sequence of twenty-fifths, fiftieths, and one-hundredths suggests that the base was conceptualized as a square of 5 units on its side and that each one unit represented a length conspicuously embedded in the length of the original long side of Hemiunu's mastaba G 4000 (Seyfzadeh, 2018).

The present investigation corroborates Gantenbrink's (1997: Figs. 2-4) observation that architectural reference points of structures within the Great Pyramid were located at the ceiling level and not the ground. Gantenbrink's argument is as follows: Only lengths measured from ceilings produces round numbers of cubits. These round numbers conformed to a theme which involve multiples of $1 / 40^{\text {th }}$ of the base of the Great Pyramid (i.e. $11 \mathrm{rc}$ ) or its height (i.e. $7 \mathrm{rc}$ ). Some lengths are based on prime numbers (Gantenbrink, 1997: Fig. 6). However, it appears as if linear distances, either based on prime numbers or multiples of 7 and 11 royal cubits, were used mostly, with a couple of exceptions, to design the horizontal dimension of structures within the Great Pyramid. The exceptions relate to the design of the $K a^{6}$ passages (alternatively called star shafts or air shafts) emanating from the King Chamber and the $11 \mathrm{rc}$ height of the ceiling joint where the descending passage meets the ascending passage (see Fig. 6 and 7 in Gantenbrink, 1997). 21/2 rc above this reference point is the top of course \#6 whose SAR is $22.65 / 25^{\text {th }}$ (Table 1 ). In other words, the cumulative height of the pyramid including the joint and the ceiling made up of course \#6 is $13 \frac{1}{2} \mathrm{rc}$.

Therefore, at course \#6, the two design principles appear to overlap. The height of the ceiling joint above ground between descending and ascending passages is both $1 / 40^{\text {th }}$ of the pyramid base, 11 rc (Gantenbrink, 1997: Fig. 6 and 8), and the stone course which covers that joint to a cumulative height of 278 inch (see Petrie, 1883, Plate VIII; sixth course cumulative height in inch: N.E. $=278.1$; S.W. $=278.4)$ to form the ceiling at that point is followed by the thicker course \#7. Gantenbrink concluded that the architect worked on a 1/40 scale to design the Great Pyramid in units of either 7 or $11 \mathrm{rc}$ and he observed that most lengths between architectural points could be derived as multiples of either unit (Gantenbrink, 1997). The question remains, why did Hemiunu employ two design principles in determining ceilings, one based on $1 / 40^{\text {th }}$ of the pyramid's key dimensions and another based on surface area ratios in $1 / 25^{\text {th }}$ ? The answer to this question ultimately has to do with how a system of lengths fits into the overall theme of how Hemiunu conceptualized the pyramid as a three-dimensional structure.

From Gantenbrink's analysis and knowing the pyramid angle, 51/2 palms per each one cubit rise, one might expect that successive courses rise by multiples of one royal cubit such that a proportional multiple of $5^{1 / 2}$ palms could be let in from the two ends of each added course's base. Surprisingly, this is not observed reviewing Petrie's plotted data of course thicknesses. Most courses are less than two royal cubits thick, but there is a large variation in thickness both above and

${ }^{6}$ In ancient Egyptian belief, the Ka was the life force of a person which left the body after death. 
below that average value. The marked variation in thickness diminishes only above the $154^{\text {th }}$ course though still interrupted by three more thickness peaks. Most courses are not a round number of royal cubits thick and so the seqed of the pyramid was probably not Hemiunu's guide to the vertical growth of the pyramid with each added course even though this may seem counterintuitive at first. Why was the ease of conforming course thickness to round numbers consistent with the seqed sacrificed for an ostensibly haphazard theme of erratically varying course thickness?

To solve this riddle, we must remind ourselves that Hemiunu appears to have employed a theme not based on lengths, as was the case for his design of horizontal dimension but based on unique surface ratios which conform to round fractions of twenty-fifths. At first look, this theme seems to contrast with the $1 / 40$ scale proposed by Gantenbrink to have guided the interior design in two dimensions. However, the two numerical themes need not be mutually exclusive since they pertain to different aspects of the overall design of the pyramid, one mostly horizontal and one vertical. This was demonstrated in the lower $2 / 5^{\text {th }}$ of the pyramid. Also, $1 / 40=25 / 1000$. Numerically therefore, the two themes are related: $1 / 40 \times 1 / 25=1 / 1000$ and $25 \times 440 \mathrm{rc} / 1000=11 \mathrm{rc}$ ! $1 / 1000$ (written with the hieroglyphs "Re/kh3") is also a factor which was evidently used to determine the aforementioned indent: $0.92 \mathrm{~m}=1.76 \mathrm{rc}=220 \mathrm{rc} \times 8 \times 1 / 1000 \sim 1 \mathrm{rc} 5$ palms 1 finger (Seyfzadeh, 2018). This factor numerically expresses the cosmogony of the Ogdoad taught at Hermopolis: The Sun over the Lotus. But an esoteric motive cannot fully explain the economic price paid by not conforming to the simple numerical rule expressed by the seqed in designing the rate of rise of each pyramid course.

Interestingly, the vertical design theme proposed here shares a feature with its horizontal counterpart proposed by Gantenbrink, namely the insistence on round-number multiples. The other feature, "suddenly" thicker courses, can now be explained as well: The likely reason for placing a series of tapering thicker stone courses above a course which formed the ceiling of an interior space was to buttress and reinforce the void's roof to prevent stone block failure under pressure from above. If this was indeed the reason, then the presence of other courses of exceptional thickness higher up in the pyramid must mark the ceilings of yet unknown voids immediately below. The pay-back, so to speak, for sacrificing the seqed as a straight-forward building principle was the perceived enhanced stability of the interior spaces inside the pyramid. The very presence, therefore, of varying course thickness, whenever this can be observed, proves that at least six if not up to ten designed spaces exist inside the pyramid at those levels, because of the cost, i.e. custom-made instead of stereo-typical thickness quarrying, incurred by not using round numbers derived from the seqed, i.e. $5 \frac{1}{2}$ rc per $7 \mathrm{rc}$. This is the main conclusion of this paper.

The second conclusion is that not all spaces in the Great Pyramid seem to have been created equally. Some spaces appear to have an added, esoteric, importance. One cannot a priori assume that architectural design must only em- 
ploy practical considerations to the exclusion of ideological, in this case theological, principles.

In a prior publication (Seyfzadeh, 2018), I argued that Hemiunu was indeed the architect of the Great Pyramid because its essential design features can be found in the design of both Hemiunu's original mastabas G 4000 and the dimensions of the larger upgrade. Here, I find new evidence to further support the idea that Hemiunu was in fact the architect of the Great Pyramid. The vertical growth of the pyramid conceptualized in units of 88 royal cubits (i.e. $5 \times 88 \mathrm{rc} \times$ $5 \times 88 \mathrm{rc}=440 \mathrm{rc} \times 440 \mathrm{rc}$ ) is a length also conspicuously embedded in G 4000's original long side (as $88 \mathrm{rc}+1 \mathrm{rc} 5$ palms 2 fingers). Furthermore, the numbers five and eight, which stand out indirectly by their absence in the numerical theme presented here based on SARs, also stand out at G 4000. Here, they are conspicuously absent from the sequence of round number fractions of twenty-fifths in the upper $3 / 5^{\text {th }}$ of the Great Pyramid even though the courses with which these ratios are associated, $\# 83$ and $\# 107$, are below distinctly thicker courses, i.e. \#84 (also \#86) and \#108, respectively (Table 1; Petrie, 1883: Plate VIII).

Of interest is that the thicker course above \#83, course \#84, aligns with the peak of the rafters above the granite tower structure over the King Chamber (Figure 4), which, once the pyramid grew past this level, was hidden from the view of even the builders since it was sealed with no access. \#83 aligns with the rafters themselves. \#83 also coincides with the approximate upper extension of a proposed void observed with Muon scanning called the "Big Void" (Morishima, et al., 2017; see the possible orientations of this proposed void in Figure 4). Therefore, it is possible that course \#107 also defines the ceiling of a, yet undiscovered, chamber. This chamber, if it exists, would have been of special significance to Hemiunu because the surface area of the course which could covers its ceiling, i.e. course \#107, relative to the pyramid's base is not a round fraction of twenty-fifths. Like the integer fraction $8 / 25^{\text {th }}$, a course with a SAR of $5 / 25^{\text {th }}$ was "omitted" from the sequence of SARs.

Not representing the numbers five and eight as round numbers in the sequence of twenty-fifths could be coincidental or it might be intentional though this is difficult to prove without other examples. In ancient Egyptian belief, Heka magic was the annunciation of certain words to activate them with real consequences for those present including Ka spirits of the deceased who were instructed to use such spells by the Pyramid Texts as they proceeded through the chambers and passages of their pyramids (Seyfzadeh \& Schoch, 2018: pp. 109-110). Certain words were avoided or phonetically embedded within others to avoid inappropriate activation. Similarly, by not expressing five and eight as round numbers designing appropriately sized surface areas at courses \#83 and \#107, Hemiunu might have wished to seal and hide chambers roofed by these courses to leave them "inactivated", but this remains speculation without further proof from other examples. My friend Nagui Guorgui, a native Egyptian, perhaps said it best in a recent conversation about this: "You don't divide a sacred 
number".

An alternative possibility to a "Secret Chamber" is that course \#107 defines the ceiling of a corridor, for example part of an internal ramp as proposed by Brier and Houdin (2008: p. 139ff.). This theory predicts period notching at the pyramid's edges during construction, where contiguous, ascending ramp corridors make ninety degree turns (Brier \& Houdin, 2008: pp. 130-132). Even though these notches were later hidden inside the fully cased pyramid, the authors identify one curious stone defect of the Great Pyramid's northeast edge easily visible today (Figure 7) which matches the position of the ninth notch in their internal ramp model and which, presumably due to internal failure and collapse at that spot, became exposed (Brier \& Houdin, 2008: pp. 137 ff.). Significantly, the floor of this notch measures $5 \times 5=25 \mathrm{rc}^{2}$, reminiscent of the concept of twenty-fifths apparently employed by Hemiunu to model the vertical design of the entire pyramid. Course \#107, however, does not run through the ceiling of this notch, but closer to its floor, which is at the $104^{\text {th }}$ course (Jean Pierre Houdin, personal communication). Also, Bob Brier was unable to detect airflow from a fissure inside the cavity causing the notch, in an area where a corridor might have been suspected based on the model. Therefore, it is not clear if this course does in fact define a corridor ceiling and if this notch indeed represents a remnant of a corner of the proposed internal ramp. Of course, it is possible that \#107 is more closely associated with the ceiling of a lower notch,

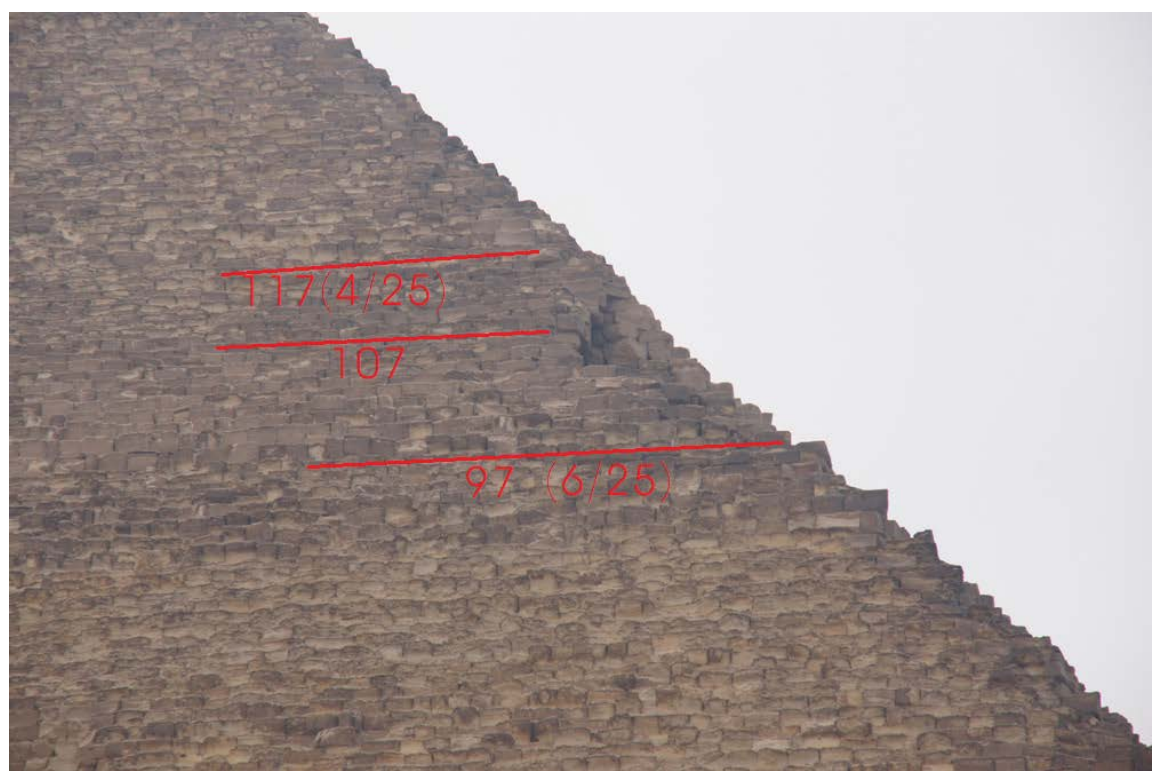

Figure 7. Northwest edge of the Great Pyramid showing the notch proposed to be an exposed turn of the internal ramp (Brier \& Housing, 2008: pp. 137-138). Indicated in red are the positions of courses \#97, 107, and 117 with SARs shown in parenthesis. Course \#107 traverses the notch approximately 3 courses above its floor. Photography (01/17/2011) by Peter Der Manuelian courtesy of Digital Giza, Harvard University; Creative Commons License. Direct link to photo:

http://gizamedia.rc.fas.harvard.edu/images/GPH/PDM\%202011/07\%20Monday\%20Jan\% 2017\%202011/PDM_2011.01.17_235.jpg. 
for example the eighth corner in the ascending spiral presumably situated at the southeast corner.

This point deserves further emphasis. Even though Petrie's measurements from all four corners suggest that the thickness of all 203 courses was uniformly varied across all stones making up those individual courses, the motivation for any variation, as it is argued here, may have been the ceiling of a space which often represents a comparatively small part of that course. The alternative of course would have been to only vary the thickness of stones above such spaces, build the rest of the course with regular blocks, and fill in the deficit with the next layer of stones. The implicit assumption of this paper is therefore that the measurable variation in the thickness of the courses based on the current exterior, accessible layer of stones are a proxy for architectural features which may reside deep in the core of the pyramid, far removed from this exterior layer and otherwise inaccessible. In other words, what one sees on the outside is a reflection of the inside.

Altogether ten courses in the upper $3 / 5^{\text {th }}$ of the Great Pyramid define levels below thickness peaks, whose SARs are round number multiples of either twenty-fifths, fifties, or hundredths. It is possible that these ten courses define the position of corridor ceilings, or the ceilings of corners were such corridors meet on the four pyramid edges, which are part of an internal spiral ramp and this ramp only commences at course \#66 whose SAR is $10 / 25^{\text {th }}$. Interestingly, Houdin's full, ground-to-summit internal ramp model predicts a total of 23 corner turns (Brier \& Houdin, 2008: p. 131) and that is the total number of thickness peaks one observes from Petrie's data including all those peaks not preceded by courses with SARs which conform to the SAR sequence of round number multiples of twenty-fifths noticed by Petrie.

Even though recent muon scanning did not detect an internal void consistent with an internal ramp (Morishima et al., 2017), such narrow voids may have escaped detection. The positive control experiment involved the detection of the upper chamber of the Bent Pyramid, but its passages were not discernible in the actual data even though they were predicted to be observable in the simulation (HIP, 2016). Therefore, any chamber smaller than the upper chamber of the Bent Pyramid relative to the length of the Muon path through solid stone may escape detection with this method. The distance traveled by incoming muons through less obstructing segments formed by any such hypothetical voids relative to the length of the path through solid stone towards the detector plates inside the Queen Chamber and in front of the pyramid at ground level was likely too short. In other words, there would not be enough difference in arrival time at the detectors between muons whether or not they traveled through a short segment of air caused by the height or width of a ramp corridor crossing the path of these particles.

Alternatively, and if not marking the ceilings of an internal ramp, it is also possible that these ten courses mark ceilings over chambers and passages smaller than the "Big Void" found by Morishima et al. (2017) just as they do in the lower 
$2 / 5^{\text {th }}$ of the Great Pyramid and were hence also missed in that study due to their relatively small size. One possible way to test these alternatives would be a new muon scan with detectors placed inside Campbell's chamber, the fifth relieving chamber above the King Chamber, or inside the cavity which produces the notch on the northeast edge of the pyramid. By reducing the measured muon paths' trajectories through solid stone, the signal-to-noise ratio will increase making such experiment a more sensitive probe of hidden voids in the upper part of the Great Pyramid than the previous one.

Finally, a few more words about the theme of twenty-fifths apparently employed by Hemiunu to conceptualize the Great Pyramid's vertical expansion. First, numerically simplifying a base of 193,600 square cubits $(440 \mathrm{rc})^{2}$ to 25 units each to represent 7744 square cubits $(88 \mathrm{rc})^{2}$ makes it easier to get a feel for the size of higher-up levels. This would have helped Hemiunu to estimate the number of stone blocks required at key levels of the growing pyramid. For example, if he was able to gauge the effort required to build a square of $88 \mathrm{rc}$, a length almost identical to the long side of his own mastaba, he could simply multiply this effort by an integer fraction of twenty-fifths to predict the time required to quarry and transport the necessary stone supply to build a given course.

Second, the sequence of twenty-fifths noted by W.M. Flinders Petrie reveals a mindset which had long been established since the time of king Djoser, alive a century before Hemiunu: That the original Egyptian pyramid was a series of mastabas each successive one somewhat smaller than the one below. If indeed round fractions of twenty-fifths designated the ceilings of conceptualized mastabas in such a stack, then the idea that each of these mastabas contained a chamber is no longer inconceivable (Nagui Guorgui, personal communication).

\section{Conclusion}

A renewed look at Petrie's data from his 1883 survey of the Great Pyramid has revealed new evidence that Hemiunu was its architect, that he computed surface area ratios and generated a sequence of round-number fractions of twenty-fifths to plan the placement of ceilings over voids in the lower parts of the pyramid, and possibly also in its upper parts. Besides this architectural application of the proposed numerical theme, he may have used numbers of theological significance in his time to mark certain areas inside the Great Pyramid where still-hidden chambers, corridors, and passages may one day be found at positions tagged with such numerical marks.

These findings permit a fascinating glimpse into the methods and thinking of an ancient architect who designed one of the most sophisticated stone structures ever conceived. Numerical tags, while alone, do not prove the existence of undiscovered internal voids inside the Great Pyramid, and may assist future researchers to non-invasively probe its interior at certain target sites with a higher chance of success. 


\section{Acknowledgements}

I would like to thank Jean-Pierre Houdin for reviewing the manuscript and for his helpful comments and critique. My thanks also to Nagui Guorgui for helpful discussions.

\section{Dedication}

To the People of Egypt.

\section{Conflicts of Interest}

The author declares no conflicts of interest regarding the publication of this paper.

\section{References}

Allen, J. P. (2005). The Ancient Egyptian Pyramid Texts. Atlanta, GA: Society of Biblical Literature.

Brier, B., \& Houdin, J.-P. (2008). The Secret of the Great Pyramid. New York: HarperCollins Publishers Inc.

Dash, G. (2012). New Angles on the Great Pyramid. AERAGRAM, 13, 10-19.

Gantenbrink, R. (1997). Ascertaining and Evaluating Relevant Structural Points Using the Cheops Pyramid as an Example. ORDO ET MENSURA CONGRESS VI-1997/DEUTSCHES MUSEUM MÜNCHEN.

http://www.cheops.org/startpage/publications/publications.htm

Heritage Innovation Preservation Institute (HIP), ScanPyramids (2016). Results from the First Measurements Campaign in the Bent Pyramid. http://www.hip.institute/press/HIP_INSTITUTE_CP7_EN.pdf

Junker, H. (1929). Giza I. Die Mastabas der IV. Dynastie auf dem Westfriedhof. Hölder-Wien und Leipzig: Pichler-Tempsky A.-G.

Krauss, R. (1997). Astronomische Konzept e und Jenseitsvorstellungen in den Pyramidentexten. Wiesbaden: Harrassowitz Verlag.

Lightbody, D. I. (2018). Is the Great Pyramid's 'Big Void' in Fact Caused by Two Construction Space Zones Flanking the Grand Gallery? Looking for Plausible Interpretations of the ScanPyramids Data Set. Working Paper. https://arkysite.files.wordpress.com/2018/04/dlightbody20181.pdf

Maragioglio, V., \& Rinaldi, C. A. (1965). L'Architetturadelle Piramidi Menfite 4. Le Grande Piramide di Cheope. Tavole. Tipografia Canessa: Rapallo.

Morishima, K., Kuno1, M., Nishio, A., Kitagawa, N., Manabe1, Y., Moto, M., Takasaki, F., Fujii, H., Satoh, K., Kodama, H., Hayashi, K., Odaka, S., Procureur, S., Attié, D., Bouteille, S., Calvet, D., Filosa, C., Magnier, P., Mandjavidze, I., Riallot, M., Marini, B., Gable, P., Date, Y., Sugiura, M., Elshayeb, Y., Elnady, T., Ezzy, M., Guerriero, E., Steiger, V., Serikoff, N., Mouret, J.-P., Charlès, B., Helal, H., \& Tayoubi, M. (2017). Discovery of a Big Void in Khufu's Pyramid by Observation of Cosmic-Ray Muons. Nature, 552, 386-390. https://doi.org/10.1038/nature24647

Petrie, W. M. F. (1883). The Pyramids and Temples of Gizeh. London: Field \& Tuer, Ye Leadenhalle Presse; Simpkin Marshall \& Co., Stationers Hall Court; Hamilton, Adams, and Co., Paternoster Row. New York: Scribner \& Welford. http://www.ronaldbirdsall.com/gizeh/petrie/index.htm 
Seyfzadeh, M. (2018). Essential Design of the Great Pyramid Encoded in Hemiunu's Mastaba at Giza. Archaeological Discovery, 6, 162-172.

https://doi.org/10.4236/ad.2018.62008

Seyfzadeh, M., \& Schoch, R. M. (2018). The Inventory Stele: More Fact than Fiction. Archaeological Discovery, 6, 103-161. https://doi.org/10.4236/ad.2018.62007 